\title{
Riqueza dos fungos ingoldianos e dos fungos aquáticos facultativos do Parque Municipal da Aclimação, São Paulo, SP, Brasil
}

\author{
Iracema Helena Schoenlein-Crusius ${ }^{1,3}$, Carolina Gasch Moreira ${ }^{1}$ e Eduardo Pereira Cabral Gomes ${ }^{2}$
}

Recebido: 12.09.2014; aceito: 27.01.2015

\begin{abstract}
Richness of ingoldian fungi and facultative aquatic fungi in the Parque Municipal da Aclimação, São Paulo, São Paulo State, Brazil). In the Parque Municipal da Aclimação, submerged mixed leaf litter samples were monthly collected from March 2007 to June 2009 at three sites of a lake where some abiotic variables were measured. In the laboratory, the leaves were washed, fragmented into aliquots $\left(1 \mathrm{~cm}^{2}\right)$, incubated in sterile distilled water for 30 days at $22^{\circ} \mathrm{C}$, and prepared on slides to be microscopically analyzed. Based on morphological characteristics, 26 fungal taxa were identified, being 16 ingoldian fungi with predominance of Lunulospora curvula Ingold, Triscelophorus monosporus Ingold, and Tripospermum myrti (Lind.) S. Hughes, and 10 facultative fungi, with Cylindrocladium scoparium Morgan, Endophragmiella sp., and Beltrania rhombica Penz as the most common taxa. The number of fungal taxa was not very different in the comparison of the main climatic seasons, but was higher at the sites next to the exit of the water treated by flotation than at a site where a more intense monitoring of the water quality becomes recommendable.
\end{abstract}

Keywords: facultative fungi, ingoldian fungi, urban lakes

RESUMO - (Riqueza dos fungos ingoldianos e dos fungos aquáticos facultativos do Parque Municipal da Aclimação, São Paulo, SP, Brasil). No Parque Municipal da Aclimação, amostras de folhedo misto submerso foram coletadas mensalmente de março de 2007 a junho de 2009 em três locais de um lago onde algumas variáveis abióticas foram medidas. No laboratório, as folhas foram lavadas, fragmentadas em alíquotas $\left(1 \mathrm{~cm}^{2}\right)$, incubadas em água destilada esterilizada durante 30 dias a $22^{\circ} \mathrm{C}$, e preparadas em lâminas para análise microscópica. Com base em características morfológicas, 26 táxons de fungos foram identificados, sendo 16 fungos ingoldianos com predomínio de Lunulospora curvula Ingold, Triscelophorus monosporus Ingold e Tripospermum myrti (Lind.) S. Hughes, e 10 facultativos, com Cylindrocladium scoparium Morgan, Endophragmiella sp. e Beltrania rhombica Penz como sendo os táxons mais comuns. Os números de táxons de fungos não diferiram muito na comparação das principais estações climáticas, mas apresentaram-se maiores nos locais próximos da saída da água tratada por flotação do que em um local cujo monitoramento mais intensivo da qualidade da água torna-se recomendável.

Palavras-chaves: fungos facultativos, fungos ingoldianos, lagos urbanos

\section{Introdução}

Os fungos ingoldianos, com seus conídios hidrodinâmicos e dependência da água para se reproduzirem, são tradicionalmente conhecidos como ativos em substratos vegetais em decomposição preferencialmente em águas lóticas límpidas e moderadamente aeradas (Ingold 1975). Porém mais recentemente a presença desses fungos anamórficos também tem sido observada em sistemas lênticos, em águas com diferentes níveis de eutrofização (Au et al. 1992, Krauss et al. 2005), tal como as águas do Parque Estadual das Fontes do Ipiranga (Schoenlein-Crusius et al. 2009) e no Parque do Ibirapuera (SchoenleinCrusius et al. 2014). Tendo em vista que a riqueza destes fungos tem contribuído para indicar o estado de conservação dos ambientes aquáticos (Burgos \& Castillo 1986, Gessner et al. 1991), justifica-se a necessidade de conhecer a diversidade das espécies nos ambientes urbanos para auxiliar o monitoramento da qualidade das águas.

Os denominados fungos aquáticos facultativos, segundo Goh \& Hyde (1996), podem ser constituídos por diferentes grupos taxonômicos conidiais, geralmente procedentes de ambientes externos da

1. Instituto de Botânica, Núcleo de Pesquisa em Micologia, Caixa Postal 68041, 04045-972 São Paulo, SP, Brasil

2. Instituto de Botânica, Núcleo de Pesquisa em Ecologia, Caixa Postal 68041, 04045-972 São Paulo, SP, Brasil

3. Autor para correspondência: iracema@crusius.com.br 
água, isto é, solo, ar ou substratos orgânicos que são carreados para o ambiente aquático. Estes fungos apresentam tolerância ao novo ambiente, podendo participar ativamente da decomposição de substratos orgânicos, contribuindo para a dinâmica nutricional do ecossistema.

Considerando que a cidade de São Paulo é muito rica em corpos d'água na forma de córregos e riachos (Sant'Anna 2000), propôs-se o levantamento da riqueza dos fungos ingoldianos e aquáticos facultativos em alguns parques municipais representativos do município, tais como o Parque do Ibirapuera, Parque do Carmo, Parque Alfredo Volpi, Parque Cidade de Toronto e também o Parque da Aclimação, sendo que o presente artigo trata somente da diversidade da micota deste último.

O Parque da Aclimação, ocupa uma área de $118.787 \mathrm{~m}^{2}$ na região central da capital paulista. A sua principal atração é um único lago central artificial, que é frequentado por diversas espécies de aves perenes e também pelas aves migratórias. A vegetação é composta por diversas espécies nativas e pequenos bosques de Ficus e de eucaliptos. Na década de 1920 o lago foi utilizado para a prática de remo e natação, além de diversas atividades sociais. Com o crescimento da metrópole, as águas do lago tornaram-se fortemente poluídas, com frequentes florações de cianobactérias (Centro de Pesquisas de História Natural 1988).

O lago central é abastecido pelos Córregos Pedra Azul e Jurubatuba, sendo que as águas são tratadas em uma unidade de flotação da SABESP. Recentemente, diversas iniciativas como o monitoramento de alguns parâmetros abióticos e bióticos do lago, reconstrução do vertedouro e recirculação das águas, entre outras, têm sido tomadas para melhorar a qualidade das águas do parque (Departamento de Controle da Qualidade Ambiental - DECONT, Prefeitura Municipal de São Paulo, 2010).

O Parque da Aclimação foi selecionado para o referido estudo devido a sua importância para a cidade e o fato de também estar sendo submetido a um extenso programa de recuperação, o qual inclui o tratamento da água dos lagos pelo método da flotação, tal como ocorre com o Parque Municipal do Ibirapuera (Schoenlein-Crusius et al. 2014). Acrescenta-se a isso um fato que não estava previsto: em fevereiro de 2009, cinco meses antes das coletas serem concluídas, ocorreu a ruptura do vertedouro do lago central, escoando água, animais e plantas, restando apenas lama e algumas pequenas poças no fundo do lago. $\mathrm{O}$ acidente modificou o cenário do lago drasticamente, oferecendo uma nova situação do ambiente estudado.

Este constitui o primeiro estudo dos fungos na água do lago do Parque da Aclimação e apresenta alguns dados abióticos medidos no período de 2007 a 2009 para fins de documentação histórica.

\section{Material e métodos}

Em março de 2007 foram estabelecidos os pontos de coleta e determinada a localização geográfica dos mesmos, às margens do lago com auxílio de aparelho GPS Garmin: local 1 (perto da entrada principal e ponto de saída da estação de flotação, 233' $22,9^{\prime \prime S}$ e 46 $37^{\prime} 42,2^{\prime \prime} \mathrm{W}$ ); local 2 (Mirante dos pombos, $23^{\circ} 34^{\prime} 26,7^{\prime \prime S}$ e 463 $7^{\prime} 39,8^{\prime \prime W}$ ) e local 3 (lado oposto do mirante dos pombos e próximo do ponto de saída

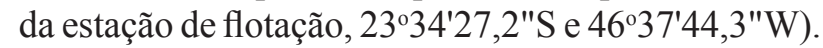
Coletas e isolamentos dos fungos - Durante 24 meses, no período de 23 de março de 2007 a 23 de junho de 2009 , foram coletadas três amostras de aproximadamente $50 \mathrm{~g}$ de folhas mistas em decomposição submersas em cada local, a uma profundidade de até $40 \mathrm{~cm}$. No laboratório, as folhas foram lavadas sob água corrente para a retirada de detritos, fragmentadas em alíquotas de até $1 \mathrm{~cm}^{2}$, colocadas em placas-de-Petri contendo água destilada esterilizada e incubadas a $22^{\circ} \mathrm{C}$ (Ingold 1975, Schoenlein-Crusius et al. 2009). A partir do terceiro dia, fragmentos das folhas foram montados entre lâmina e lamínula, com água, para observação de estruturas de valor taxonômico sob microscópio óptico e identificação dos táxons através da consulta de chaves específicas (Nilsson 1964, Ingold 1975, Marvanová 1997). Para fins de preservação e documentação dos táxons encontrados, os fragmentos analisados foram montados lâminas semi-permanentes em resina de álcool polivinílico.

Medição de algumas variáveis abióticas- Concomitantemente à coleta das amostras de folhas, foram medidas temperatura, $\mathrm{pH}$, teor de oxigênio dissolvido e condutividade da água com auxílio de equipamento multisonda modelo U10 da Horiba.

As condições climáticas citadas no presente estudo baseiam-se nos dados meteorológicos de chuvas, temperatura e umidade relativa do ar fornecidos pelo Instituto Astronômico e Geofísico da Universidade de São Paulo, detalhados em Schoenlein-Crusius et al. (2014).

Análise dos dados - As variáveis abióticas dos três locais de amostragem foram comparadas por Análise 
de Variância de um fator (ANOVA um fator) a 5\% de probabilidade. Antes da análise os dados foram avaliados quanto à premissa do teste e quando necessário as transformações foram feitas para a realização do mesmo. Os testes foram realizados no programa estatístico PAST versão 2.17 (Hammer et al. 2001). A partir da matriz similaridade de Jaccard da listagem de espécies ao longo de todo o período para os três locais foi feita uma análise de agrupamento utilizando-se o método de ligação por média de grupo.

\section{Resultados e Discussão}

De acordo com os dados meteorológicos apresentados por Schoenlein-Crusius et al. (2014), durante o período de estudo, ocorreram épocas chuvosas e quentes nos períodos de outubro de 2007 a fevereiro de 2008 e de outubro de 2008 a março de 2009. Épocas secas e frias ocorreram nos meses de agosto a setembro de 2007 e no mês de julho de 2008. No frio mês de julho de 2007 foi registrado o acúmulo de 160,9 mm de chuvas, considerado elevado para essa época. Também em abril de 2008 ocorreu um pico de chuvas, acumulando 121,8 mm naquele mês. A umidade relativa do ar (\%) variou entre $74,1 \%$ e $82,6 \%$, acompanhando as flutuações da precipitação pluviométrica no período estudado. A caracterização climática dos meses de coleta no presente estudo foi realizada com base nos dados climáticos acima mencionados.

Variáveis abióticas - a tabela 1 apresenta os valores individuais, valores médios mensais e valores médios em cada local, da temperatura $\left({ }^{\circ} \mathrm{C}\right)$ e do $\mathrm{pH}$ mensurados durante as coletas de amostras de folhedo misto na água do Lago da Aclimação.

Os valores médios mensais mínimos e máximos da temperatura da água variaram de $17,3{ }^{\circ} \mathrm{C}$ em junho de 2008 (época chuvosa e fria) a $26,0{ }^{\circ} \mathrm{C}$ em abril de 2008 (época chuvosa e quente). As variações máximas e mínimas da temperatura nos locais de coleta acompanharam estas flutuações, ocorrendo praticamente nos mesmos meses. Os valores médios dos locais de coleta variaram de $21,9{ }^{\circ} \mathrm{C}$ (local 2) a $22,3{ }^{\circ} \mathrm{C}$ (local 3 ), com pequenas variações.

As variações dos valores médios da temperatura no Parque da Aclimação são semelhantes aos citados por Apolinário (1984), que se estenderam na faixa entre 10 e $24{ }^{\circ} \mathrm{C}$ no estudo das leveduras em águas que abastecem várias estações de tratamento de água na cidade de São Paulo. Valores semelhantes também foram medidos no Lago das Ninféias no Parque
Estadual das Fontes do Ipiranga (Bicudo et al. 2002, Rocha 2004).

Com relação ao pH (tabela 1), os valores médios mensais variaram de 6,87, em maio de 2007 (época seca e fria) a 10,3, em agosto de 2007 (época seca e fria também). Em todos os locais de coleta os valores máximos do $\mathrm{pH}$, isto é, 10,3 ocorreram em agosto de 2007. No local 2 e 3 o valor individual mínimo do $\mathrm{pH}$, correspondente a 6,75 ocorreu em maio de 2007 e no local 1, o valor mínimo 6,94 foi medido em março de 2009. Comparando os valores médios mensais dos locais de coleta, os valores variaram entre 8,0 e 8,1, revelando que as águas do Parque da Aclimação tendem a ser mais alcalinas, isto é, com valores acima de 7,0. Águas com a mesma tendência foram encontradas por Medeiros (2005) no Lago da Carioca, Rio Doce e Rio Piracicaba, por Rocha (2004) e Moreira (2006) no Lago das Garças no Parque Estadual das Fontes do Ipiranga, SP e por Gruppi (2008) no Parque Central em Santo André, SP.

Com relação à condutividade na água (tabela 2), os valores médios mensais variaram de $0,120 \mu \mathrm{Scm}^{3}$ em fevereiro de 2008 (época chuvosa e quente), março de 2008 (época seca e quente) e janeiro de 2009 (época chuvosa e quente) a $0,251 \mu \mathrm{Scm}^{3} \mathrm{em}$ outubro de 2007 (época seca e quente) e setembro de 2008 (época seca e fria). Com relação aos locais de coleta, os valores médios considerando o período total do estudo, variaram pouco, situando-se entre $0,189 \mu \mathrm{Scm}^{3}$ (local 2) a $0,192 \mu \mathrm{Scm}^{3}$ (local 3), sendo que os valores máximos e mínimos individuais e os valores médios mensais medidos em cada local de coleta ocorreram praticamente nos mesmos meses. Os valores da condutividade elétrica medida nas águas do Lago da Aclimação mostraram-se compatíveis com os citados para outros parques urbanos em São Paulo (Bicudo et al. 2002, Rocha 2004, Moreira 2006, Schoenlein-Crusius et al. 2009).

Os valores médios mensais do teor de oxigênio dissolvido (tabela 2) variaram de $1,96 \mathrm{mgO}_{2} \cdot \mathrm{L}^{-1} \mathrm{em}$ agosto de 2007 (época seca e fria) a 15,59 mgO . $^{-1}$ em setembro de 2008 (época seca e fria). Os valores máximos e mínimos individuais e os valores médios mensais medidos em cada local de coleta ocorreram praticamente nos mesmos meses. Com relação aos valores médios do teor de oxigênio dissolvido na água de cada local de coleta foram observadas poucas variações, estendendo-se de $7,39 \mathrm{mgO}_{2} \cdot \mathrm{L}^{-1}$ (local 2) a $7,74 \mathrm{mgO}_{2} \cdot \mathrm{L}^{-1}$ (local 1) durante todo o período estudado. Os teores de oxigênio dissolvido são compatíveis com os mensurados em águas de 
outros parques urbanos (Bicudo et al. 2002, Rocha 2004, Moreira 2006, Schoenlein-Crusius et al. 2009, Schoenlein-Crusius et al. 2014).

O mês de agosto de 2007 apresentou valores mais elevados do $\mathrm{pH}$ (valor médio de 10,3), de condutividade (valor médio de 0,245 ) e os menores valores médios de oxigênio dissolvido $\left(1,96 \mathrm{mgO}_{2} \cdot \mathrm{L}^{-1}\right)$, indicando que naquele mês pode ter havido alguma ocorrência ainda desconhecida que acarretou estes resultados. Quando a concentração de oxigênio atinge níveis mais baixos $\left(4 \mathrm{mg}^{-1}\right)$ os processos anaeróbios passam a ser os mais importantes, pois produzem grande quantidade compostos redutores, que para serem oxidados também consomem grande quantidade de oxigênio (Esteves 1998). No entanto, teores de oxigênio abaixo de $2,0 \mathrm{mgO}_{2} \cdot \mathrm{L}^{-1}$ ocorreram somente em agosto de 2007, estando as amostras restantes em conformidade com as condições das águas de classe 4 da Resolução CONAMA.

Apesar da flutuação dos valores das variáveis abióticas ao longo do período de coleta elas não mostraram diferenças significativas entre os três locais de coleta: temperatura (Anova 1 fator, 2 g.l., $\mathrm{F}=0,116, \mathrm{p}=0,89$ ); $\mathrm{pH}$ (Anova 1 fator, 2 g.l., $\mathrm{F}=0,130, \mathrm{p}=0,99$ ); condutividade (Anova 1 fator, 2 g.l., $F=0,019, p=0,982$ ); e oxigênio (Anova 1 fator, 2 g.l., $F=0,069, \mathrm{p}=0,933)$.

Mesmo após ter ocorrido o esvaziamento do lago no mês de fevereiro de 2009, expondo o sedimento, aproximadamente um mês depois, em março de 2009,

Tabela 1. Valores individuais e médios da temperatura $\left({ }^{\circ} \mathrm{C}\right)$ e $\mathrm{pH}$ da água do lago no Parque Municipal da Aclimação, São Paulo, SP, Brasil, de maio/2007 a junho/2009.

Table 1. Individual and mean values of the temperature $\left({ }^{\circ} \mathrm{C}\right)$ and $\mathrm{pH}$ of the lake water in the Parque Municipal da Aclimação, São Paulo, São Paulo State, Brazil, from May 2007 to June 2009.

\begin{tabular}{|c|c|c|c|c|c|c|c|c|c|c|}
\hline \multirow{2}{*}{ Número da coleta } & \multirow{2}{*}{ Data } & \multirow{2}{*}{ Condições climáticas } & \multicolumn{5}{|c|}{ Temperatura $\left({ }^{\circ} \mathrm{C}\right)$} & \multicolumn{3}{|c|}{$\mathrm{pH}$} \\
\hline & & & Local 1 & Local 2 & Local 3 & Médias & Local 1 & Local 2 & Local 3 & Médias \\
\hline 1 & 24.05 .07 & seca e fria & 18,6 & 18,5 & 18,5 & 18,5 & 7,12 & 6,75 & 6,75 & 6,87 \\
\hline 2 & 02.07 .07 & chuvosa e fria & 20,3 & 21,0 & 20,5 & 20,6 & 7,90 & 7,80 & 8,10 & 7,93 \\
\hline 3 & 27.08 .07 & seca e fria & 24,5 & 24,0 & 23,7 & 24,1 & 10,2 & 10,3 & 10,3 & 10,3 \\
\hline 4 & 04.10 .07 & seca e quente & 23,6 & 23,5 & 23,1 & 23,4 & 7,06 & 7,17 & 7,10 & 7,11 \\
\hline 5 & 30.11 .07 & chuvosa e quente & 23,5 & 22,1 & 24,0 & 23,2 & 7,37 & 7,54 & 7,30 & 7,40 \\
\hline 6 & 20.12 .07 & chuvosa e quente & 23,0 & 23,0 & 23,0 & 23,0 & 7,60 & 7,40 & 7,30 & 7,43 \\
\hline 7 & 23.01 .08 & chuvosa e quente & 23,0 & 22,0 & 23,0 & 22,7 & 7,00 & 7,10 & 7,30 & 7,13 \\
\hline 8 & 21.02 .08 & chuvosa e quente & 25,0 & 25,0 & 25,0 & 25,0 & 7,30 & 7,20 & 7,20 & 7,23 \\
\hline 9 & 11.03 .08 & seca e quente & 26,0 & 25,0 & 26,0 & 25,7 & 7,70 & 7,50 & 7,30 & 7,50 \\
\hline 10 & 22.04 .08 & chuvosa e quente & 26,0 & 26,0 & 26,0 & 26,0 & 8,40 & 8,60 & 8,40 & 8,47 \\
\hline 11 & 12.05 .08 & seca e fria & 19,2 & 19,1 & 18,9 & 19,1 & 8,59 & 8,65 & 8,45 & 8,56 \\
\hline 12 & 25.06 .08 & seca e fria & 17,0 & 18,0 & 17,0 & 17,3 & 6,80 & 7,30 & 7,40 & 7,17 \\
\hline 13 & 24.07 .08 & seca e fria & 19,6 & 15,5 & 20,0 & 18,4 & 9,00 & 8,90 & 9,10 & 9,00 \\
\hline 14 & 27.08 .08 & seca e fria & 21,3 & 21,0 & 21,8 & 21,4 & 8,66 & 8,48 & 8,54 & 8,56 \\
\hline 15 & 24.09 .08 & seca e fria & 19,9 & 19,6 & 19,5 & 19,7 & 9,88 & 9,76 & 9,66 & 9,77 \\
\hline 16 & 30.10 .08 & chuvosa e quente & 23,6 & 23,6 & 24,0 & 23,7 & 9,48 & 9,58 & 9,60 & 9,55 \\
\hline 17 & 19.11 .08 & chuvosa e quente & 22,2 & 22,6 & 22,4 & 22,4 & 9,30 & 9,30 & 9,34 & 9,31 \\
\hline 18 & 16.12 .08 & chuvosa e quente & 23,2 & 23,1 & 23,2 & 23,2 & 9,56 & 9,40 & 9,48 & 9,48 \\
\hline 19 & 28.01 .09 & chuvosa e quente & 23,4 & 23,3 & 23,3 & 23,3 & 7,26 & 7,39 & 7,42 & 7,36 \\
\hline 21 & 25.03 .09 & chuvosa e quente & 23,5 & 23,4 & 24,6 & 23,8 & 6,94 & 7,31 & 7,57 & 7,27 \\
\hline 22 & 28.04 .09 & seca e fria & 24,2 & 24,8 & 24,3 & 24,4 & 7,51 & 7,61 & 7,74 & 7,62 \\
\hline 23 & 26.05 .09 & seca e fria & 21,7 & 21,7 & 21,7 & 21,7 & 7,38 & 7,79 & 7,60 & 7,59 \\
\hline 24 & 24.06 .09 & seca e fria & 18,2 & 18,2 & 18,4 & 18,3 & 7,27 & 7,41 & 7,32 & 7,33 \\
\hline & Médias & & 22,2 & 21,9 & 22,3 & & 8,00 & 8,10 & 8,10 & \\
\hline
\end{tabular}


os valores das variáveis abióticas medidas na água após o novo enchimento, mostraram-se semelhantes aos mensurados nos demais meses, indicando uma rápida recuperação do corpo d'água após o incidente.

Os resultados aqui apresentados referentes aos parâmetros abióticos estão de acordo com o Relatório de Qualidade do Meio Ambiente (RQMA) de 2010 (Departamento de Controle da Qualidade Ambiental DECONT, Prefeitura Municipal de São Paulo), no qual na maioria dos meses, o índice de qualidade das águas apresentou-se regular a boa, sendo que o teor de oxigênio dissolvido foi considerado compatível para a vida aquática, apesar da demanda bioquímica de oxigênio (DBO) ter-se revelado elevada nos locais de coleta. Também é fato concordante que o $\mathrm{pH}$ da água varia de neutro a alcalino e o restabelecimento rápido das condições abióticas do lago nos meses que seguiram ao extravasamento do mesmo em fevereiro de 2009.

Diversidade dos fungos - no texto e nas tabelas o número de táxons de fungos é procedente da contagem direta dos mesmos, enquanto o número de ocorrências refere-se à contagem de quantas vezes determinado táxon foi registrado em uma dada situação. No Parque Municipal da Aclimação foram registradas 51 ocorrências de 16 táxons de fungos ingoldianos (tabela 3) e 20 ocorrências de 10 táxons de fungos aquáticos facultativos (tabela 4), perfazendo o total de 26 táxons de fungos, registrados em 71 ocorrências durante todo o período de estudo (tabela 5). A riqueza de espécies é semelhante, porém o número de

Tabela 2. Valores individuais e médios da condutividade $\left(\mu \mathrm{Scm}^{3}\right)$ e do oxigênio dissolvido $\left(\mathrm{mgO}_{2} \cdot \mathrm{L}^{-1}\right)$ da água do lago no Parque Municipal da Aclimação, São Paulo, SP, Brasil, de maio/2007 a junho/2009.

Table 2. Individual and mean values of the conductivity $\left(\mu \mathrm{Scm}^{3}\right)$ and dissolved oxygen $\left(\mathrm{mgO}_{2} \mathrm{~L}^{-1}\right)$ of the lake water in the Parque Municipal da Aclimação, São Paulo, São Paulo State, Brazil, from May 2007 to June 2009.

\begin{tabular}{|c|c|c|c|c|c|c|c|c|c|c|}
\hline \multirow{2}{*}{ Número da coleta } & \multirow{2}{*}{ Data } & \multirow{2}{*}{ Condições climáticas } & \multicolumn{4}{|c|}{ Condutividade $\left(\mu \mathrm{Scm}^{3}\right)$} & \multicolumn{4}{|c|}{ Oxigênio dissolvido $\left(\mathrm{mgO}_{2} \mathrm{~L}^{-1}\right)$} \\
\hline & & & Local 1 & Local 2 & Local 3 & Médias & Local 1 & Local 2 & Local 3 & Médias \\
\hline 1 & 24.05 .07 & seca e fria & 0,144 & 0,142 & 0,142 & 0,143 & - & - & - & - \\
\hline 2 & 02.07 .07 & chuvosa e fria & 0,200 & 0,200 & 0,205 & 0,202 & 8,91 & 8,00 & 8,00 & 8,30 \\
\hline 3 & 27.08 .07 & seca e fria & 0,254 & 0,239 & 0,242 & 0,245 & 1,99 & 1,89 & 1,99 & 1,96 \\
\hline 4 & 04.10 .07 & seca e quente & 0,250 & 0,250 & 0,252 & 0,251 & 4,70 & 4,76 & 3,88 & 4,45 \\
\hline 5 & 30.11 .07 & chuvosa e quente & 0,210 & 0,211 & 0,210 & 0,210 & 5,45 & 5,65 & 5,70 & 5,60 \\
\hline 6 & 20.12 .07 & chuvosa e quente & 0,200 & 0,200 & 0,200 & 0,200 & 5,20 & 4,40 & 3,00 & 4,20 \\
\hline 7 & 23.01 .08 & chuvosa e quente & 0,140 & 0,140 & 0,130 & 0,144 & 4,80 & 5,60 & 4,50 & 4,97 \\
\hline 8 & 21.02 .08 & chuvosa e quente & 0,120 & 0,120 & 0,120 & 0,120 & 6,90 & 6,50 & 5,00 & 6,13 \\
\hline 9 & 11.03 .08 & seca e quente & 0,120 & 0,120 & 0,120 & 0,120 & 6,90 & 5,00 & 5,20 & 5,70 \\
\hline 10 & 22.04 .08 & chuvosa e quente & 0,160 & 0,160 & 0,170 & 0,163 & 10,20 & 10,00 & 10,20 & 10,13 \\
\hline 11 & 12.05 .08 & seca e fria & 0,168 & 0,172 & 0,169 & 0,169 & 10,20 & 10,12 & 10,79 & 10,37 \\
\hline 12 & 25.06 .08 & seca e fria & 0,180 & 0,180 & 0,200 & 0,187 & 9,70 & 8,90 & 9,20 & 9,27 \\
\hline 13 & 24.07 .08 & seca e fria & 0,200 & 0,200 & 0,210 & 0,203 & 13,72 & 12,81 & 15,45 & 13,99 \\
\hline 14 & 27.08 .08 & seca e fria & 0,227 & 0,214 & 0,214 & 0,218 & 14,60 & 11,00 & 12,22 & 12,61 \\
\hline 15 & 24.09 .08 & seca e fria & 0,253 & 0,249 & 0,250 & 0,251 & 15,88 & 15,17 & 15,72 & 15,59 \\
\hline 16 & 30.10 .08 & chuvosa e quente & 0,243 & 0,242 & 0,243 & 0,243 & 10,72 & 9,83 & 9,31 & 9,95 \\
\hline 17 & 19.11 .08 & chuvosa e quente & 0,231 & 0,224 & 0,231 & 0,228 & 9,28 & 9,10 & 8,85 & 9,07 \\
\hline 18 & 16.12 .08 & chuvosa e quente & 0,198 & 0,199 & 0,200 & 0,199 & 9,20 & 8,62 & 10,60 & 9,47 \\
\hline 19 & 28.01 .09 & chuvosa e quente & 0,120 & 0,119 & 0,122 & 0,120 & 3,69 & 3,71 & 4,82 & 4,07 \\
\hline 21 & 25.03 .09 & chuvosa e quente & 0,161 & 0,157 & 0,162 & 0,160 & 7,23 & 7,49 & 6,24 & 6,98 \\
\hline 22 & 28.04 .09 & seca e fria & 0,194 & 0,198 & 0,197 & 0,196 & 6,90 & 7,50 & 7,79 & 7,39 \\
\hline 23 & 26.05 .09 & seca e fria & 0,208 & 0,207 & 0,208 & 0,207 & 5,38 & 6,45 & 5,18 & 5,67 \\
\hline 24 & 24.06 .09 & seca e fria & 0,221 & 0,218 & 0,217 & 0,218 & 5,61 & 6,98 & 6,35 & 6,31 \\
\hline & Médias & & 0,191 & 0,189 & 0,192 & & 7,74 & 7,39 & 7,42 & \\
\hline
\end{tabular}


ocorrências é menor do que a encontrada no Parque Municipal do Ibirapuera, onde foram contabilizadas por Schoenlein-Crusius et al. (2014) 104 ocorrências de 27 táxons, divididos em 15 fungos ingoldianos e 12 aquáticos facultativos.

Os fungos ingoldianos (tabela 3 ) que se fizeram presentes em maior número de meses foram Lunulospora curvula Ingold (15 ocorrências), seguida por Triscelophorus monosporus Ingold (sete ocorrências), Tripospermum myrti (Lind) S. Hughes (seis ocorrências) e Triscelophorus acuminatus Nawawi (quatro ocorrências). Os táxons que compõem a micota associada às folhas em decomposição submersas nas águas do Parque da Aclimação já foram observados em diversos outros ambientes aquáticos urbanos (Schoenlein-Crusius \& Malosso, 2007, Schoenlein-Crusius et al. 2009, Schoenlein-Crusius et al. 2014). Porém destaca-se a ocorrência de Blodgettia indica Subram., um fungo raro que no continente sul americano foi encontrado anteriormente por Matsushima (1993) no Equador e também observado e descrito a partir de amostras de folhedo misto submerso no Parque Municipal Alfredo Volpi (Moreira \& Schoenlein-Crusius 2012).

As espécies de Lunulospora e de Triscelophorus geralmente apresentam grande ocorrência nos levantamentos de fungos ingoldianos nos trópicos (Schoenlein-Crusius \& Grandi, 2003). Lunulospora curvula já foi observada em diversos tipos de folhas coletadas na Mata Atlântica (Schoenlein-Crusius et al. 2009). Lunulospora cymbiformis K. Miura é menos comum, mas já foi citada em folhedo coletado de ambientes aquáticos de cerrado (Malosso 1999, Schoenlein-Crusius, 2002) e também na Mata Atlântica de planalto (Schoenlein-Crusius et al. 2009).
O maior número de táxons de fungos ingoldianos (tabela 3 ), correspondente a 12 , ocorreu no local 1 , mas o maior número de ocorrências, isto é, 23 , no local 3, enquanto o menor número de táxons (seis) e de ocorrências (sete) ocorreu no local 2, que é o mais afastado da saída da estação de flotação e onde se localiza um mirante e muitas aves. Em ordem decrescente, o maior número de táxons, 12 (22 ocorrências), foi obtido nos meses chuvosos e quentes, seguido pelos 11 táxons (24 ocorrências) obtidos nos meses secos e frios, três táxons (três ocorrências) nos meses secos e quentes e dois táxons (duas ocorrências) nos meses chuvosos e frios.

Nos meses secos e frios foram observados 11 táxons de fungos ingoldianos (tabela 3), incluindo quatro exclusivos, Anguillospora crassa Ingold, Anguillospora sp., Lunulospora cymbiformis K. Miura e Tetrachaetum elegans Ingold. Cinco, entre 12 táxons, foram observados exclusivamente nos meses chuvosos e quentes, Blodgettia indica Subram., Flabellospora crassa Alas., Flagellospora curvula Ingold, Lunulospora sp. e Varicosporium elodae W. Kegel.

Estes resultados assemelham-se aos observados nas águas do Parque do Ibirapuera (SchoenleinCrusius et al. 2014), onde o número de táxons de fungos ingoldianos apresentou-se maior nas épocas mais quentes e chuvosas, contrariando a literatura no que diz respeito à maior preferência dos mesmos às épocas mais frias (Ingold 1975, Bärlocher 1992). Possivelmente, a associação da maior riqueza destes fungos nas épocas de outono e primavera nos países de clima temperado, se deva mais à maior disponibilidade de folhas senescentes nos corpos d'água nessas épocas do que somente pelo decréscimo da temperatura.
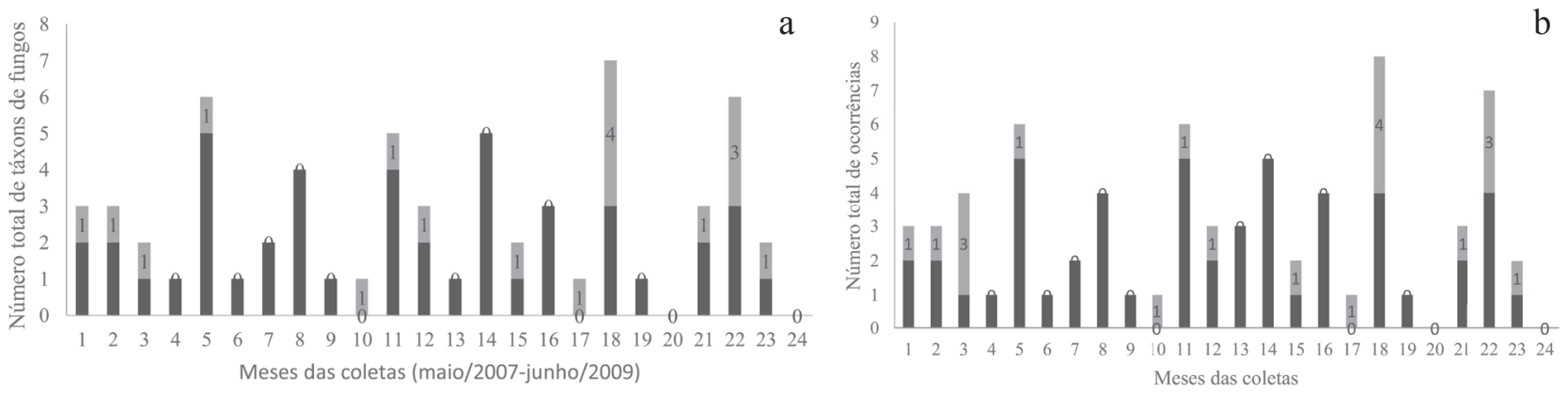

Figura 1. Números de táxons (a) e de ocorrências (b) de fungos ingoldianos e facultativos observados no folhedo misto submerso coletado no lago no Parque Municipal da Aclimação, São Paulo, SP, Brasil, de maio de 2007 a junho de 2009. Legenda: Barras cinza escuro: fungos ingoldianos; barras cinza claro: fungos aquáticos facultativos.

Figure 1. Number of taxa (a) and occurrences (b) of ingoldian and facultative fungi observed in the submerged leaf litter collected in the lake of the Parque Municipal da Aclimação, São Paulo, São Paulo State, Brazil, from May 2007 to June 2009. Legend: Dark gray bars: ingoldian fungi; light gray bars: facultative aquatic fungi. 
Nos trópicos geralmente o maior aporte de matéria orgânica alóctone ocorre nas épocas chuvosas que no sudeste brasileiro coincide com as épocas mais quentes.

Sob ponto de vista das épocas sazonais, porém levando em conta os locais de coleta (tabela 3) nos meses secos e frios verificou-se que o número de táxons e de ocorrências dos fungos ingoldianos foi semelhante entre o local 1 (sete táxons com 11 ocorrências) e 3 (seis táxons com nove ocorrências) e menor no local 2 (três táxons com quatro ocorrências). Resultado semelhante foi verificado nos meses chuvosos e quentes, registrando-se sete táxons com nove ocorrências no local 1 , sete táxons com 11 ocorrências no local 3 e dois táxons (duas ocorrências) no local 2, portanto não evidenciando claramente alguma influência da caracterização climática dos meses sobre o número de táxons e de ocorrências dos fungos ingoldianos.

Nos meses chuvosos e frios foram registrados somente dois táxons (duas ocorrências) no local 3 e nos meses secos e quentes observou-se a ocorrência única de um táxon em cada local de coleta, possivelmente em decorrência do número de meses caracterizados como chuvosos e frios (um mês) e os secos e quentes (dois meses) ser menor do que o número de meses das outras épocas, correspondente a 10 meses secos e frios e 10 meses chuvosos e quentes (tabela 3).

Os fungos aquáticos facultativos (tabela 4) que ocorreram em maior número de meses foram Cylindrocladium scoparium Morgan (quatro ocorrências), Endophragmiella sp e Beltrania rhombica Penz (três ocorrências cada), sendo que os demais se fizeram presentes de forma esporádica.

Os representantes de Beltrania são considerados bastante complexos devido às suas características taxonômicas. No presente estudo foi possível identificar Beltrania rhombica Penz., mas outro isolado do mesmo gênero não apresentou características morfológicas típicas (dimensões dos conídios) que permitissem a confirmação da espécie. Assim como Beltrania, as espécies de Cylindrocladium têm ocorrido como fungos aquáticos facultativos em diversos substratos e ambientes aquáticos na mata atlântica (Schoenlein-Crusius \& Milanez 1998, Schoenlein-Crusius et al. 2009).

Endophragmiella foi observada em diversos levantamentos na Mata Atlântica de Paranapiacaba, SP em São Paulo (Capelari et al. 2009) e também tem sido frequente em ambientes urbanos (Schoenlein-Crusius et al. 2009).
Em ordem decrescente, seis táxons de fungos aquáticos facultativos (11 ocorrências) foram observados nos meses secos e frios, cinco (oito ocorrências), nos meses chuvosos e quentes e somente um táxon (uma ocorrência) em mês chuvoso e frio (tabela 4).

Entre seis ou sete táxons, quatro ocorreram exclusivamente nos meses secos e frios, Beltrania rhombica Penz., Cylindrocladium parvum P. J. Anderson, Nigrospora oryzae (Berk. \& Broome) Petch e Phoma sp.; Beltrania sp., Epicoccum nigrum Link e Fusarium aquaeductum (Rabenh. \& Radlk.) foram observados exclusivamente nos meses chuvosos e quentes.

O número de táxons de fungos facultativos (cinco nos locais 1 e 2, e quatro táxons no local 3) variou pouco entre os locais de coleta, mas o número de ocorrências (10) apresentou-se maior no local 1 do que nos demais locais de coleta. Nos meses secos e frios o número de táxons (quatro) e de ocorrências (seis) apresentou-se maior no local 1 do que nos demais locais, o que não foi verificado nos meses chuvosos e quentes, nos quais ocorreram dois táxons em todos os locais de coleta, excetuando o local 1, onde o número de ocorrências (quatro) foi maior do que nos demais locais de coleta (tabela 4). Nos meses chuvosos e frios ocorreu somente um táxon no local 2. De forma diferente, no Parque Municipal do

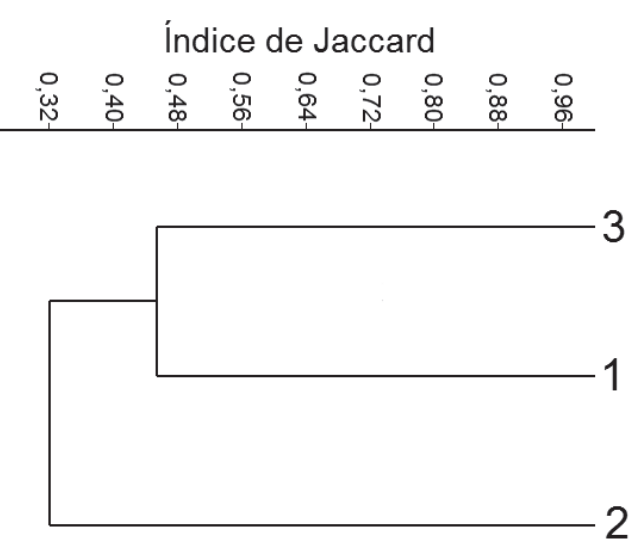

Figura 2. Dendrogram dos locais de coleta, de acordo com o índice de similaridade de Jaccard, referentes à micota total observada no folhedo misto submerso coletado no Parque da Aclimação em São Paulo, SP, Brasil.

Figure 2. Dendrogramm of the collection sites, according to the Jaccard's similarity index, regarding the total mycota observed in the submerged leaf litter collected in the Parque da Aclimação in São Paulo, São Paulo State, Brazil. 
Ibirapuera, ocorreram os maiores números de táxons de fungos facultativos nas épocas mais frias e secas (maio e agosto de 2008) e em locais mais eutrofizados (Schoenlein-Crusius et al. 2014).

Somando os dados referentes aos fungos ingoldianos e os facultativos (tabela 5), observa-se que nos meses secos e frios e nos chuvosos e quentes, foram obtidos 17 táxons, com respectivamente 35 e 30 ocorrências, e que nos demais meses foram verificados três táxons (três ocorrências) tanto nos meses chuvosos e frios, quanto nos meses secos e quentes. Estes resultados corroboram com os obtidos no Parque Municipal do Ibirapuera (SchoenleinCrusius et al. 2014) onde a micota associada a folhedo misto submerso apresentou a tendência de ser mais rica nos meses chuvosos e quentes do que nos secos e frios e com o comportamento da micota verificado no Parque Estadual das Fontes do Ipiranga (SchoenleinCrusius et al. 2009) cuja riqueza claramente variou de acordo com o local de coleta.

No local 1 foram contabilizados 17 táxons totais (31 ocorrências), seguido por 15 táxons (27

Tabela 3. Ocorrências de fungos ingoldianos em folhedo misto submerso no lago do Parque Municipal da Aclimação, São Paulo, SP, Brasil, de maio/2007 a junho/2009 (meses de 1 a 24). O: soma das ocorrências dos táxons nos locais de coleta; 1,3,11,12,13,14,15,22,23,24: meses secos e frios; $5,6,7,8,10,16,17,18,19,21$ : meses chuvosos e quentes; 2 : mês chuvoso e frio; 4,9: meses secos e quentes; * número total de táxons excluindo repetições.

Table 3. Occurrences of ingoldian fungi in submerged mixed leaf litter in the lake of the Parque Municipal da Aclimação, São Paulo, São Paulo State, Brazil, from May 2007 to June 2009 (months, from 1 to 24). O: sum of the occurrences of the taxa in the collection sites; $1,3,11,12,13,14,15,22,23,24$ : dry and cold months; 5,6,7,8,10,16,17,18,19,21: rainy and hot months; 2: rainy and cold month; 4,9: dry and hot months; * total number of taxa excluding repetition.

\begin{tabular}{|c|c|c|c|c|}
\hline Táxons/Locais de coleta & 1 & 2 & 3 & $\mathrm{O}$ \\
\hline \multicolumn{5}{|l|}{ Fungos ingoldianos } \\
\hline Anguillospora crassa Ingold & & & 1 & 1 \\
\hline Anguillospora longuissima (Sacc. \& Syd.) Ingold & 11 & 14 & 5 & 3 \\
\hline Anguillospora sp. & & 14 & & 1 \\
\hline Blodgettia indica Subram. & 6 & & & 1 \\
\hline Flabellospora crassa Alas. & & & $8,19,21$ & 3 \\
\hline Flagellospora curvula Ingold & & & 5 & 1 \\
\hline Flagellospora penicillioides Ingold & 22 & & 16 & 2 \\
\hline Lunulospora curvula Ingold & $3,8,11,13,22$ & 12,13 & $2,5,11,13,14,16,21,22$ & 15 \\
\hline Lunulospora. cymbiformis K. Miura & 22 & & & 1 \\
\hline Lunulospora sp. & 18 & & 18 & 2 \\
\hline Margaritispora aquatica Ingold & 5 & & 1 & 2 \\
\hline Tetrachaetum elegans Ingold & 15 & & & 1 \\
\hline Tripospermum myrti (Lind) S. Hughes & 5,7 & 4 & $2,9,23$ & 6 \\
\hline Triscelophorus acuminatus Nawawi & 11 & 8 & 7,14 & 4 \\
\hline Triscelophorus monosporus Ingold & $9,11,14,16,18$ & 16 & 12 & 7 \\
\hline Varicosporium elodeae W. Kegel & 18 & & & 1 \\
\hline $\mathrm{N}^{\circ}$ total de táxons & 12 & 6 & 11 & $16^{*}$ \\
\hline $\mathrm{N}^{\circ}$ de táxons nos meses secos e frios & 7 & 3 & 6 & $11^{*}$ \\
\hline $\mathrm{N}^{\circ}$ de táxons nos meses chuvosos e quentes & 7 & 2 & 7 & $12^{*}$ \\
\hline $\mathrm{N}^{\circ}$ de táxons nos meses chuvosos e frios & 0 & 0 & 2 & $2 *$ \\
\hline $\mathrm{N}^{o}$ de táxons nos meses secos e quentes & 1 & 1 & 1 & $3 *$ \\
\hline $\mathrm{N}^{o}$ total de ocorrências & 21 & 7 & 23 & 51 \\
\hline $\mathrm{N}^{\circ}$ de ocorrências nos meses secos e frios & 11 & 4 & 9 & 24 \\
\hline $\mathrm{N}^{\circ}$ de ocorrências nos meses chuvosos e quentes & 9 & 2 & 11 & 22 \\
\hline $\mathrm{N}^{\circ}$ de ocorrências nos meses chuvosos e frios & 0 & 0 & 2 & 2 \\
\hline No de ocorrências nos meses secos e quentes & 1 & 1 & 1 & 3 \\
\hline
\end{tabular}


ocorrências) no local 3 e 11 táxons (13 ocorrências) no local 2 (tabela 5). Nos meses secos e frios foram obtidos 11 táxons (17 ocorrências) no local 1, oito táxons (11 ocorrências) no local 3 e seis (sete ocorrências) no local 2. Nos meses chuvosos e quentes foram observados nove táxons (13 ocorrências) nos locais 1 e 3 , enquanto no local 2 foram obtidos quatro táxons (quatro ocorrências). Nos meses chuvosos e frios foram observados somente dois táxons (duas ocorrências) no local 3 e um táxon (uma ocorrência) no local 2. Nos meses secos e quentes foi observado um táxon (uma ocorrência) em cada local de coleta (tabela 5). No estudo conduzido no Parque do Ibirapuera, as condições climáticas, seguido pelo grau de eutrofização foram relevantes para a composição da micota, verificando-se que amostras de locais de coleta em diferentes meses divergiram mais do que entre os locais em uma determinada estação climática (Schoenlein-Crusius et al. 2014).

De acordo com os dados organizados em função dos meses de coleta (figura 1), o maior número total de táxons, sete, ocorreu em dezembro de 2008 (18 $8^{\mathrm{a}}$ coleta). O maior número de táxons de fungos ingoldianos (cinco táxons) ocorreu em novembro de 2007 ( $5^{\mathrm{a}}$ coleta) e agosto de 2008 ( $14^{\mathrm{a}}$ coleta), e a ausência foi registrada em abril ( $10^{\mathrm{a}}$ coleta $)$, novembro de 2008 ( $17^{\mathrm{a}}$ coleta) e fevereiro de 2009 ( $20^{\mathrm{a}}$ coleta). O maior número de táxons e de ocorrências (quatro) dos fungos facultativos foi registrado em dezembro de 2008 ( $18^{\mathrm{a}}$ coleta), e as ausências nos meses de outubro (4 $4^{\mathrm{a}}$ coleta), dezembro de 2007 ( $6^{\mathrm{a}}$ coleta), janeiro a março de 2008 ( $7^{\mathrm{a}}, 8^{\mathrm{a}}$ e $9^{\mathrm{a}}$ coletas $)$, julho e agosto de 2008 ( $13^{\mathrm{a}}$ e $14^{\mathrm{a}}$ coletas $)$, outubro de 2008 $\left(16^{\mathrm{a}}\right.$ coleta), janeiro e fevereiro de $2009\left(19^{\mathrm{a}}\right.$ e $20^{\mathrm{a}}$

Tabela 4. Ocorrências de fungos aquáticos facultativos em folhedo misto submerso no lago do Parque Municipal da Aclimação, São Paulo, SP, Brasil, de maio/2007 a junho/2009 (meses de 1 a 24). O: soma das ocorrências dos táxons nos locais de coleta; $1,3,11,12,13,14,15,22,23,24$ : meses secos e frios; $5,6,7,8,10,16,17,18,19,21$ : meses chuvosos e quentes; 2: mês chuvoso e frio; 4,9: meses secos e quentes. * número total de táxons excluindo repetições.

Table 4. Occurrences of aquatic facultative fungi in submerged mixed leaf litter in the lake of the Parque Municipal da Aclimação, São Paulo, São Paulo State, Brazil, from May 2007 to June 2009 (months, from 1 to 24). O: sum of the occurrences of the taxa in the collection sites; $1,3,11,12,13,14,15,22,23,24$ : dry and cold months; 5,6,7,8,10,16,17,18,19,21: rainy and hot months; 2: rainy and cold month; 4,9: dry and hot months; * total number of taxa excluding repetition.

\begin{tabular}{|c|c|c|c|c|}
\hline Táxons/Locais de coleta & 1 & 2 & 3 & $\mathrm{O}$ \\
\hline \multicolumn{5}{|l|}{ Fungos aquáticos facultativos } \\
\hline Beltrania rhombica Penz. & 22,23 & & 12 & 3 \\
\hline Beltrania sp. & & & 18 & 1 \\
\hline Cylindrocladium parvum P. J. Anderson & & 11 & & 1 \\
\hline Cylindrocladium scoparium Morgan & $10,15,21,22$ & & & 4 \\
\hline Endophragmiella sp. & & 18,22 & 17 & 3 \\
\hline Epicoccum nigrum Link & 5,18 & & & 2 \\
\hline Fungo dematiáceo $\mathrm{n}^{\circ} 1$ & & 2 & & 1 \\
\hline Fusarium aquaeductuum (Rabenh. \& Radlk.) Lagerh. \& Rabenh. & & 18 & & 1 \\
\hline Nigrospora oryzae (Berk. \& Broome) Petch & 1 & & & 1 \\
\hline Phoma sp. & 3 & 3 & 3 & 1 \\
\hline $\mathrm{N}^{\circ}$ de táxons de fungos facultativos & 5 & 5 & 4 & $10^{*}$ \\
\hline $\mathrm{N}^{\circ}$ de táxons nos meses secos e frios & 4 & 3 & 2 & $6^{*}$ \\
\hline $\mathrm{N}^{\circ}$ de táxons nos meses chuvosos e quentes & 2 & 2 & 2 & $5^{*}$ \\
\hline $\mathrm{N}^{\circ}$ de táxons nos meses chuvosos e frios & 0 & 1 & 0 & $1 *$ \\
\hline $\mathrm{N}^{o}$ de táxons nos meses secos e quentes & 0 & 0 & 0 & 0 \\
\hline $\mathrm{N}^{o}$ de ocorrências de fungos facultativos & 10 & 6 & 4 & 20 \\
\hline $\mathrm{N}^{\circ}$ de ocorrências na época seca e fria & 6 & 3 & 2 & 11 \\
\hline $\mathrm{N}^{o}$ de ocorrências na época chuvosa e quente & 4 & 2 & 2 & 8 \\
\hline $\mathrm{N}^{o}$ de ocorrências na época chuvosa e fria & 0 & 1 & 0 & 1 \\
\hline $\mathrm{N}^{\circ}$ de ocorrências na época seca e quente & 0 & 0 & 0 & 0 \\
\hline
\end{tabular}


coletas). O fato de não terem sido observados fungos em algumas amostras não significa necessariamente que os mesmos não estavam presentes nas mesmas, mas que nas condições metodológicas do presente estudo e apesar da grande plasticidade, a ocorrência dos mesmos não foi registrada. De fato, nas amostras coletadas nas poças de água remanescentes, um dia após o esvaziamento acidental do lago, em fevereiro de 2009 ( $20^{\text {a }}$ coleta), foi observada intensa profusão de bactérias e protozoários, mas não o desenvolvimento de fungos. Posteriormente, em abril de $2009\left(22^{\mathrm{a}}\right.$ coleta), imediatamente após o lago ter sido novamente abastecido, foram observados seis táxons, distribuídos em sete ocorrências, mas em junho de 2009 (24 coleta), novamente a ausência dos fungos.

O índice de similaridade de Jaccard maior (53,3\%) ocorreu na comparação dos fungos ingoldianos observados nos locais 1 e 3 e o menor (38,5\%) entre os locais 1 e 2 (tabela 6). De forma semelhante, o maior índice $(67 \%)$ ocorreu na comparação dos fungos facultativos observados nos locais 1 e 3 e o menor (28,6\%) entre os locais 1 e 2 , levando o mesmo resultado na comparação da somatória do táxons de fungos. O maior índice de similaridade (45,5\%) ocorreu entre os fungos totais observados nos locais 1 e 3 e o menor (27,3\%) na comparação dos fungos totais observados nos locais 1 e 2 . Estes resultados revelam que os locais 1 e 3 apresentaram semelhança na composição da micota do que o local 2 , bem diferente principalmente quanto aos fungos aquáticos facultativos, o que foi muito bem evidenciado pelo dendrograma apresentado na figura 2.

Em um levantamento de Hyphomycetes aquáticos realizado nas águas do Parque Estadual das Fontes do Ipiranga em São Paulo (Schoenlein-Crusius et al. 2009), o maior número de táxons de fungos ingoldianos foram observados nos meses de maio e novembro de 2004, épocas climaticamente distintas, não se evidenciando uma influência clara entre a ocorrência dos fungos e os meses de coleta, caracterizados quanto às condições climáticas. Porém o índice de similaridade de Sörensen revelou valores reduzidos, isto é, menores do que 50\% na comparação entre as micotas, indicando que a composição da micota variou consideravelmente entre os meses. Portanto, ao se avaliar o efeito da sazonalidade sobre a diversidade dos fungos precisa ser levado em conta não só o número de táxons, mas a composição da micota.

O Relatório de Qualidade do Meio Ambiente (RQMA) de 2010 (Departamento de Controle da Qualidade Ambiental - DECONT, Prefeitura Municipal de São Paulo) não especificou os locais nos quais as amostras para monitoramento foram

Tabela 5. Número de táxons e de ocorrências totais dos fungos ingoldianos somados aos dos fungos aquáticos facultativos do folhedo misto submerso no lago do Parque Municipal da Aclimação, São Paulo, SP, Brasil, de maio/2007 a junho/2009.

* número total de táxons excluindo repetições.

Table 5. Total number of taxa and occurrences of ingoldian fungi added to aquatic facultative fungi of submerged mixed leaf litter in the lake of the Parque Municipal da Aclimação, São Paulo, São Paulo State, Brazil, from May 2007 to June 2009.

* total number of taxa excluding repetition.

\begin{tabular}{|c|c|c|c|c|}
\hline Táxons / Locais de coleta & 1 & 2 & 3 & Totais \\
\hline \multicolumn{5}{|l|}{ Fungos ingoldianos + facultativos } \\
\hline Número total de táxons & 17 & 11 & 15 & $26^{*}$ \\
\hline $\mathrm{N}^{\circ}$ de táxons na época seca e fria & 11 & 6 & 8 & $17^{*}$ \\
\hline$N^{o}$ de táxons na época chuvosa e quente & 9 & 4 & 9 & $17 *$ \\
\hline $\mathrm{N}^{o}$ de táxons na época chuvosa e fria & 0 & 1 & 2 & $3 *$ \\
\hline $\mathrm{N}^{0}$ de táxons na época seca e quente & 1 & 1 & 1 & $3 *$ \\
\hline Número total de ocorrências & 31 & 13 & 27 & 71 \\
\hline $\mathrm{N}^{o}$ de ocorrências na época seca e fria & 17 & 7 & 11 & 35 \\
\hline $\mathrm{N}^{o}$ de ocorrências na época chuvosa e quente & 13 & 4 & 13 & 30 \\
\hline $\mathrm{N}^{o}$ de ocorrências na época chuvosa e fria & 0 & 1 & 2 & 3 \\
\hline $\mathrm{N}^{\circ}$ de ocorrências na época seca e quente & 1 & 1 & 1 & 3 \\
\hline
\end{tabular}


Tabela 6. Índices de similaridade de Jaccard (\%) entre táxons de fungos ingoldianos, facultativos e micota total no folhedo misto submerso coletado nos locais de coleta no lago do Parque Municipal da Aclimação, São Paulo, SP, Brasil.

Table 6. Jaccard's similarity index (\%) between ingoldian and facultative fungal taxa and total mycota in the submerged mixed leaf litter collected at the sites in the lake in the Parque Municipal da Aclimação in São Paulo, São Paulo State, Brazil.

\begin{tabular}{ccccccc}
\hline \multirow{2}{*}{ Locais } & \multicolumn{2}{c}{ Ingoldianos } & \multicolumn{2}{c}{ Facultativos } & \multicolumn{2}{c}{ Totais } \\
\cline { 2 - 7 } & 2 & 3 & 2 & 3 & 2 & 3 \\
\hline \multirow{2}{*}{1} & 38,5 & 53,3 & 11,1 & 28,6 & 27,3 & 45,5 \\
2 & & 41,7 & & 28,6 & & 36,8 \\
& & & & & & \\
\hline
\end{tabular}

coletadas, indicando de forma generalizada que o índice de qualidade da água (IQA) do lago central se manteve entre regular e bom durante o período estudado. Aquele monitoramento também revelou que a demanda bioquímica de oxigênio mostrou-se elevada, ocasionando a diminuição do IQA da água do lago central da Aclimação em alguns meses. As variáveis abióticas medidas no presente estudo corroboram com esses dados, porém os resultados referentes aos fungos indicam diferenças entre os locais de coleta (figura 2), destacando-se negativamente o local 2 , com menor número de táxons e de ocorrências.

O local 2 situa-se no mirante dos pombos e é o mais afastado da estação de flotação e ainda não há dados adicionais suficientes que possam embasar uma análise científica mais detalhada sobre as causas dessa situação. A título de mera especulação, poderia se supor que a presença maciça de aves neste local afete a quantidade e ocorrência dos fungos, tal como foi verificado por Ninomiya et al. (1993) no levantamento de fungos no solo afetado pela população de garças e socós às margens do Lago das Garças situado no Parque Estadual das Fontes do Ipiranga (PEFI). Naquele estudo o número total de colônias de fungos apresentou-se maior no solo afetado pelos excrementos, porém a riqueza dos fungos foi menor, indicando haver condições consideravelmente restritivas naquele ambiente. $\mathrm{Na}$ mesma área do PEFI, no Lago das Garças, SchoenleinCrusius et al. (2009), verificaram que primordialmente a elevação da eutrofização das águas pode acarretar uma diminuição da similaridade entre as micotas, atribuída à presença de espécies capazes de colonizar folhas em decomposição, mesmo em condições de elevada poluição, resultado semelhante ao encontrado no Parque da Aclimação.

A micota do lago da Aclimação é composta por espécies de fungos bastante comuns, já encontradas em águas de outros ambientes urbanos com e sem tratamento pela flotação, indicando que as águas do Parque da Aclimação conservam a diversidade dos fungos, tão necessária para que relevantes processos como a decomposição da matéria orgânica alóctone possam acontecer. Também no Parque do Ibirapuera, o processo de flotação pode ter acarretado mudanças na composição da micota, mas não na sua riqueza, expressa pelo número de táxons (Schoenlein-Crusius et al. 2014).

As águas do Parque da Aclimação têm sido monitoradas quanto à sua qualidade e uma série de melhorias tem sido conduzida na área, tais como a construção de um novo vertedouro, aumento do volume de água tratada, entre outras. O presente trabalho retrata somente a situação dos fungos presentes nas águas em dado período, não permitindo extrapolações, mas encoraja que se dê especial atenção à área do mirante dos pombos entre os locais de monitoramento rotineiro realizado pelas instâncias competentes. Encoraja também a continuidade do monitoramento da qualidade da água de médio a longo prazo para que haja melhor embasamento técnico e científico para se compreender de forma mais detalhada as variações da diversidade de fungos, diante das influências antrópicas intrínsecas desta área, cuja conservação é tão importante para a qualidade de vida da cidade de São Paulo.

\section{Agradecimentos}

Os autores agradecem ao Departamento de Áreas Verdes da Prefeitura do Município de São Paulo, pela autorização e à Sra. Emy Yoshimoto, pelo apoio à presente pesquisa; e ao CNPq, pela bolsa de produtividade para a da primeira autora (processo 306923/2006-8).

\section{Literatura citada}

Apolinário, M.E.S. 1984. Levantamento de leveduras e leveduróides de corpos d'água da região da grande São Paulo. Dissertação de Mestrado, Universidade Estadual Paulista, Rio Claro. 
Au, D.W.T., Hodkiss, I.J. \& Vrijmoed, L.L.P. 1992. Fungi and cellulolytic activity with decomposition of Bauhinia purpurea leaf litter in a polluted and unpolluted Hong Kong waterway. Canadian Journal of Botany 70: 1071-1079.

Bärlocher, F. 1992. Research on aquatic Hyphomycetes: historical background and overview. In F. Bärlocher. The Ecology of aquatic Hyphomycetes. Springer Verlag, Berlin, pp. 1-15.

Bicudo, D.C., Forti, M.C., Carmo, C.F., Bourotte, C., Forti, C.E.M., Melfi, A.J. \& Lucas, Y. 2002. A atmosfera, as águas superficiais e os reservatórios no PEFI: caracterização química. In: D.C. Bicudo, M.C. Forti \& C.E.M. Bicudo (eds.). Parque Estadual das Fontes do Ipiranga (PEFI): unidade de conservação que resiste à urbanização de São Paulo. Secretaria do Meio Ambiente do Estado de São Paulo, São Paulo, pp. 161-200.

Burgos, E.J. \& Castillo, P.H. 1986. Hyphomycetes acuaticos como indicadores de contaminacion. Biota 2: 1-10, 1986.

Capelari, M,, Grandi, R.A P., Gugliotta, A., PiresZottarelli, C.L.A. \& Schoenlein-Crusius, I.H. 2009. Fungos: diversidade. In: M.I.M.S. Lopes, M. Kirizawa \& M.M.R.F. Melo (orgs.). Patrimônio da Reserva Biológica do Alto da Serra de Paranapiacaba, a antiga Estação Biológica do Alto da Serra. Governo do Estado de São Paulo, Secretaria do Meio Ambiente, Instituto de Botânica, pp. 216-228.

Centro de Pesquisas de História Natural. 1988. Conheça o verde. Supervisão de Goro Hashimoto. CPHN, São Paulo, fascículos 1-15.

Departamento de Controle da Qualidade Ambiental - DECONT. 2010. Relatório de Qualidade do Meio Ambiente (RQMA). Prefeitura municipal de São Paulo. Disponível em http://www.prefeitura.sp.gov.br/cidade/ secretarias/upload/chamadas/relatorio_decont_web\%20 novo_1268761581.pdf (acesso em DİA-MÊS-ANO).

Esteves, F.A. 1998. Fundamentos da limnologia. Editora Interciência Ltda., Rio de Janeiro.

Gessner, M.O., Bauchrowitz, M.A. \& Escautier, M. 1991. Extraction and quantification of ergosterol as a measure of fungal biomass in leaf litter. Microbial Ecology 22: 285-291.

Goh, T.K. \& Hyde, K.D. 1996. Biodiversity of freshwater fungi. Journal of Industrial Microbiology 17: 328-345

Gruppi, V. 2008. Diversidade de fungos microscópicos em folhedo submerso de lagos do Parque Central no município de Santo André, SP, Brasil. Monografia de Bacharelado, Universidade Metodista, São Bernardo do Campo.

Hammer, Ø., Harper, D.A.T., Ryan, P.D. 2001. PAST: Paleontological statistics software package for education and data analysis. Palaeontologia Electronica 4(1):1-9. http://palaeo-electronica.org/2001_1/past/issue1_01. htm (acesso em 14 de julho de 2014).
Ingold, C.T. 1975. An Illustrated Guide to Aquatic and Water-borne Hyphomycetes (Fungi Imperfecti) with notes on their Biology. Freshwater Biological Association n. 30, Ambleside, UK.

Malosso, E. 1999. Hyphomycetes em ambientes aquáticos lótico e lêntico - ocorrência e biomassa. Dissertação de Mestrado, Universidade Federal de São Carlos, São Carlos.

Marvanová, L. 1997. Freshwater Hyphomycetes: a survey with remarks on tropical taxa. In: K.K. Janardhanan, C. Rajendran, K. Natarajan \& D.L. Hawsworth (eds.). Tropical Mycology, Science Publishers Inc.

Matsushima, T. 1993. Matsushima Mycological Memoirs no. 7 , Kobe.

Medeiros, A.O. 2005. Influência de impactos antrópicos em fungos isolados em ambientes aquáticos. Tese de Doutorado, Universidade Federal de Minas Gerais, Belo Horizonte.

Moreira, C.G. 2006. Avaliação da diversidade e biomassa de fungos associados a folhas em decomposição de Tibouchina pulchra Cogn. submersas em reservatórios do Parque Estadual das Fontes do Ipiranga (PEFI), São Paulo, SP. Dissertação de Mestrado, Instituto de Botânica, São Paulo.

Moreira, C.G. \& Schoenlein-Crusius, I.H. 2012. Nova espécie e novos registros para o Brasil de hifomicetos em folhedo submerse coletados no Parque Municipal Alfredo Volpi, São Paulo, SP, Brasil. Hoehnea 39: 521-527.

Nilsson, S. 1964. Freshwater Hyphomycetes. Symbolae Botanicae Upsalienses 18: 1-130.

Ninomiya, A., Antunes, M.F.R. \& Schoenlein-Crusius, I.H. 1993. Fungi from soil affected by birds in the "Parque Estadual das Fontes do Ipiranga", São Paulo State, Brazil. Revista de Microbiologia 24: 49-53.

Rocha, M. 2004. Micota zoospórica de lagos com diferentes trofias no Parque Estadual das Fontes do Ipiranga (PEFI), São Paulo, SP. Dissertação de Mestrado, Universidade de São Paulo, São Paulo.

Sant'Anna, D.B. 2000. Cidade das Águas - usos de rios, córregos, bicas e chafarizes em São Paulo (1822-1901). 1 ed. SENAC, São Paulo.

Schoenlein-Crusius, I.H. 2002. Aquatic Hyphomycetes from cerrado regions in the state of São Paulo, Brazil. Mycotaxon 81: 457-462.

Schoenlein-Crusius, I.H. \& Grandi, R.A.P. 2003. The diversity of aquatic Hyphomycetes in South America. Brazilian Journal of Microbiology 34: 183-193.

Schoenlein-Crusius, I.H. \& Malosso, E. 2007. Diversity of Aquatic Hyphomycetes in the tropics. In: B.N. Ganguli \& S.K. Deshmukh (eds.). Fungi: multifaceted microbes. Anamaya Publishers, New Delhi, pp. 61-81. 
Schoenlein-Crusius, I.H. \& Milanez, A.I. 1998. Fungal succession on leaves of Alchornea triplinervia (Spreng.) M. Arg. Submerged in a stream of an Atlantic Rainforest in the State of São Paulo, Brazil. Revista Brasileira de Botânica 21: 253-259.

Schoenlein-Crusius, I.H., Milanez, A.I., Trufem, S.F.B. \& Pires-Zottarelli, C.L.A. 2009. Fungos: estudos ecológicos. In: M.I.M.S. Lopes, M. Kirizawa \& M.M.R.F. Melo (orgs.). Patrimônio da Reserva Biológica do Alto da Serra de Paranapiacaba, a antiga Estação Biológica do Alto da Serra. Governo do Estado de São Paulo, Secretaria do Meio Ambiente, Instituto de Botânica, pp. 233-241.
Schoenlein-Crusius, I.H., Moreira, C.M. \& Bicudo, D.C. 2009. Aquatic Hyphomycetes in the "Parque Estadual das Fontes do Ipiranga" - PEFI, São Paulo, Brazil. Revista Brasileira de Botânica 32: 411-426.

Schoenlein-Crusius, I.H., Moreira, C.G. \& PiresZottarelli, C.L.A. 2007. O papel dos fungos nos ecossistemas aquáticos. Boletim da Sociedade Brasileira de Limnologia 36: 26-30.

Schoenlein-Crusius, I.H, Moreira, C.G., Takahashi, J.P. \& Gomes, E.P.C. 2014. Riqueza dos fungos ingoldianos e aquáticos facultativos no Parque Municipal do Ibirapuera, São Paulo, SP, Brasil. Hoehnea 41: 61-76. 